\title{
Effect of stimulus duration on vibrotactile sensation magnitude
}

\author{
RONALD T. VERRILLO and ROBERT L. SMITH \\ Institute for Sensory Research, Syracuse University, Syracuse, New York 13210
}

\begin{abstract}
The method of magnitude estimation was used to determine the growth of vibrotactile sensation as a function of stimulus intensity at four burst durations. Measurements were made at a frequency of $250 \mathrm{~Hz}$ over the right thenar eminence of seven subjects. Results show that the resultant power functions grow slightly steeper as stimulus duration decreases and that vibrotactile sensation magnitude at ail ievels of intensity tested reaches a maximum at approximately $600 \mathrm{msec}$. The results are compared to previous research reports and discussed in terms of temporal summation theory.
\end{abstract}

The temporal course of sensation magnitude for vibrotactile stimulation consists of an initial increase during approximately the first second of stimulation followed by a gradual decline to some asymptotic value (von Békésy, 1959). We are concerned in this experiment with the initial phase of the phenomenon, that is, those changes in subjective intensity that occur within the first second of stimulation. Numerous investigations of the effects of duration have been reported for vision (Mansfield, 1973; Raab, 1962; Stevens \& Hall, 1966), audition (Port, 1963; Stevens \& Hall, 1966; Wright, 1965; and others), proprioception (Brown, 1966), and several other sense modalities. Verrillo (1965) determined that vibrotactile thresholds decreased with increasing duration up to about $600 \mathrm{msec}$, which agreed with Zwislocki's (1960) theory of temporal summation at threshold. Using a direct scaling procedure, Berglund, Berglund, and Ekman (1967) measured the effect of stimulus duration on the subjective magnitude of suprathreshold vibrotactile stimuli delivered to the finger. They showed the subjective intensity of a $250-\mathrm{Hz}$ signal to be a logarithmic function of stimulus duration up to about $1.0 \mathrm{sec}$. Maximum subjective intensity was reached between 200 and $1,200 \mathrm{msec}$, with a median value of approximately $700 \mathrm{msec}$. This result is in agreement with the value reported by Verrillo (1965) for threshold measurements, but contrasts with von Békésy's (1959) value of $1,200 \mathrm{msec}$ obtained by using a matching procedure.

The exponents of the psychophysical power functions reported by Berglund et al. (1967) decreased from .7 for the shortest duration $(30 \mathrm{msec})$ to .4 for durations of $220 \mathrm{msec}$ or longer. Gescheider (1976) reported exponent values of .40 for a duration of $600 \mathrm{msec}$ and .43 for durations of 200 and $50 \mathrm{msec}$, using the method of magnitude estimation.

This research was supported by Grant NS-09940 from the National Institutes of Health, U.S. Department of Health, Education, and Welfare.
The present study was designed to investigate by the method of magnitude estimation the effect of stimulus duration upon the subjective magnitude of vibrotactile stimuli.

\section{METHOD AND PROCEDURE}

The apparatus used in this experiment has been described in detail in a previous publication (Verrillo, Fraioli, \& Smith, 1969). Sinusoidal vibrations $(250 \mathrm{~Hz})$ were delivered to the thenar eminence of the right hands of seven subjects through a $2.9-\mathrm{cm}^{2}$ circular contactor. The subjects were asked to assign numbers (magnitude estimation) to a randomly presented series of nine intensities ranging from 2.0 to $40 \mathrm{~dB}$ above threshold. No reference standard or modulus was used in order to minimize the biases inherent in such a procedure (Hellman \& Zwislocki, 1961, 1963; Stevens, 1956). The random series of intensities was presented three times at four stimulus durations: 10,80 , 600 , and $900 \mathrm{msec}$ measured at the $1 / 2$ power point. Each session was confined to a single duration. After discarding the first run of each set, the geometric mean of Runs 2 and 3 was taken and plotted as a function of sensation level. The data presented are geometric means calculated over the performance of seven subjects.

\section{RESULTS AND DISCUSSION}

The results shown in Figure 1 are the geometric means of magnitude estimations plotted as a function of sensation level. The numerical estimates made by seven subjects were not normalized. Data points are shown for stimulus durations of $10,80,600$, and $900 \mathrm{msec}$ taken at a frequency of $250 \mathrm{~Hz}$. In Figure 2 the data are replotted as a function of absolute displacement in order that individual curves for duration may be seen and compared more easily. The data points for the $900-\mathrm{msec}$ duration have been omitted in Figure 2 in the interest of clarity, since they closely approximate those of $600 \mathrm{msec}$. The slope values in the upper portions of the curves are $.47, .49$, and .50 for durations of 600 , 80 , and $10 \mathrm{msec}$, respectively. The range of slope values for the individual subjects across all conditions was .40 to .71 . The lower portions of the curves all approached a slope value of unity in agreement with the prediction 


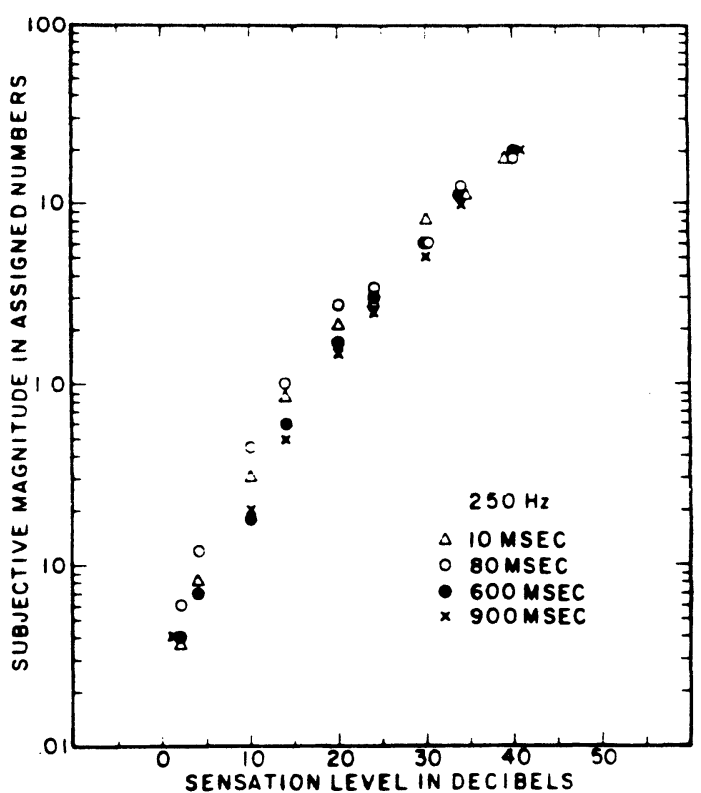

Figure 1. Magnitude estimation of subjective intensity of vibration plotted as a function of sensation level at $250 \mathrm{~Hz}$. Geometric means of the non-normalized numerical estimates of seven subjects are shown for the stimulus durations, 10, 80, 600 , and $900 \mathrm{msec}$.

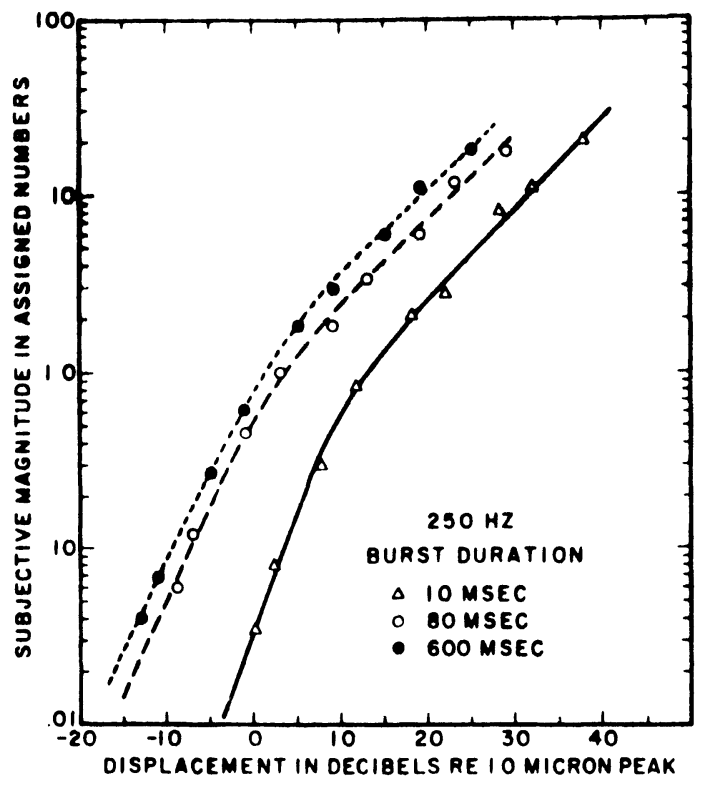

Figure 2. Magnitude estimation data for three burst durations plotted as a function of absolute displacement. Curves drawn through the data points have upper slope values of .47 for a duration of $600 \mathrm{msec}, .49$ for $80 \mathrm{msec}$, and .50 for $10 \mathrm{msec}$.

made by Zwislocki's (1960, 1965; Hellman \& Zwislocki, 1961) theory of temporal summation. At near threshold intensities, the sensation is directly proportional to energy.

The slope values shown in Figure 2 are in reasonable agreement with those reported by Gescheider (1976), who reported values of .40 for a $600-\mathrm{msec}$ duration and
43 for a 50-msec burst. At long burst durations, the data agree reasonably with Berglund et al. (1967), who found a slope of .42 for a $600-\mathrm{msec}$ duration, but at shorter durations there is considerable disparity. Berglund et al. report a slope of .69 for a burst duration of $30 \mathrm{msec}$. The discrepancies might be accounted for by the differences in experimental procedures between the two studies. Berglund et al. studied the fingertip with a $.5-\mathrm{cm}^{2}$ contactor without surround; the thenar eminence was stimulated using a $2.9-\mathrm{cm}^{2}$ contactor with surround in the present study. However, the presence or absence of a surround at the fingertip appears to have little effect on the detection threshold or the slope of subjective magnitude (Verrillo, 1974; Verrillo \& Chamberlain, 1972), and the use of a small contactor has little effect on the frequency response at the fingertip (Verrillo, 1971). Alternatively, the use of a restricted range of intensities ( 32 to $54 \mathrm{~dB} \mathrm{SL}$ ) in the Berglund et al. study may have contributed to the steeper curves they found (Poulton, 1968). Finally, a finger-span procedure was used in the Berglund et al. study, whereas measurements in the present study were made by the method of direct numerical magnitude estimation. The difference in methodology may have contributed to the observed differences in the data.

The data are replotted in Figure 3 to show threshold and equal sensation contours as a function of burst duration. It illustrates how stimulus duration affects the sensation magnitude of vibrotactile stimulation at threshold and at eight levels of intensity above threshold. Results reported by Gescheider (1976) at 50 and $200 \mathrm{msec}$ and by Capraro (unpublished) at $20 \mathrm{msec}$ are also included in the graph. The results of Gescheider and Capraro are in reasonable agreement with our data. Berglund et al. (1967), Gescheider (1976), and the present study all show that maximum subjective intensity is produced in the vicinity of a 600 -msec duration, which contrasts with von Békésy's (1959) maxi-

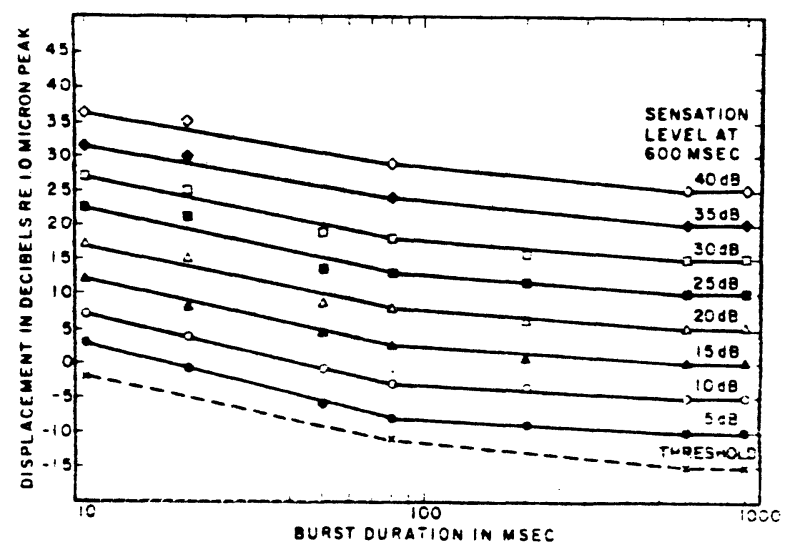

Figure 3. Equal sensation contours for vibrotaction at $250 \mathrm{~Hz}$ plotted as a function of stimulus burst duration. The sensation levels refer to a duration of $600 \mathrm{msec}$. The data shown at 50 and 200-msec durations are derived from Gescheider (1976) and the 20-msec data points are from unpublished results of A. J. Capraro. 
mum of 1.0 to $2.0 \mathrm{sec}$. The curves are approximately parallel throughout the range of intensities, which seems to imply that the temporal summation of energy observed near threshold also occurs at suprathreshold intensities. On the other hand, the subjective magnitude functions are directly proportional to energy near threshold, but become compressed at higher intensity levels (Figures 1 and 2). Hence a simple interpretation in terms of energy summation may not be tenable at the higher levels of intensity, i.e., a peripheral compression would be expected to produce steeper equal sensation contours (Zwislocki, 1969). In order to explain a similar anomaly involving the temporal summation of loudness, Zwislocki hypothesized that a neural adaptation process counteracted peripheral compression. Since Pacinian corpuscles, which are activated by the high frequency signals $(250 \mathrm{~Hz})$, do not show adaptation effects (Lindblom \& Lund, 1966; Talbot, Darian-Smith, Kornhuber, \& Mountcastle, 1968), they would have to occur in the central nervous system. An alternate explanation would place the site of the compression central to that of the temporal summation. However, presently available data are insufficient to allow any conclusions to be drawn.

\section{REFERENCES}

Berglund, B.. Berglund, U., \& Ekman, G. Temporal integration of vibrotactile stimulation: Perceptual and Motor Skills. 1967, 25, 549-560.

Brown, J. H. Magnitude estimation of angular velocity during passive rotation. Journal of Experimental Psychology, 1966, 72, 169-172.

Gescheider, G. A. Evidence in support of the duplex theory of mechanoreception. Sensory Processes, 1976, 1, 68-76.

Hellman. R. P., \& Zwislocki, J. Some factors affecting the estimation of loudness. Journal of the Acoustical Society of America, 1961, 33, 087-694.

Hellman, R. P., \& Zwislocki, J. J. Monaural loudness function at $1,000 \mathrm{cps}$ and interaural summation. Journal of the Acoustical Society of America, 1963, 35, 856-865.

Lindblom, U., \& Lund, L. The discharge from vibrationsensitive receptors in the monkey foot. Experimental Neurology, 1966, 15, 401-417.
MANSFiEld, R. J. W. Brightness function: Effect of area and duration. Journal of the Optical Society of America, 1973. 63, 913-920.

Port, E. Ueber die Lautstarke Einzelner Kurzer Schallimpulse. Acoustica, 1963, 13, 212-223.

Poulton, E. C. The new psychophysics: Six models for magnitude estimation. Psychological Bulletin, 1968, 69, 1-19.

RAAB, D. H. Magnitude estimation of the brightness of brief foveal stimuli. Science, 1962, 135, 42-44.

Stevens. J. C.. \& Hall, J. W. Brightness and loudness as a function of stimulus duration. Perception \& Psychophysics. 1966, 1. 319-327.

Stevens, S. S. The direct estimation of sensory magnitudesloudness. American Journal of Psychology, 1956, 69. 1-25.

Talbot, W. H., Darian-Smith, I., Kornhuber, H. H., \& Mountcastle, V. B. The sense of flutter-vibration: Comparison of the human capacity with response patterns of mechano-receptive afferents from the monkey hand. Journal of Neurophysiology, 1968, 31, 301-334.

VerRILlo, R. T. Temporal summation in vibrotactile sensitivity. Journal of the Acoustical Society of America, 1965. 37, 843-846.

VerRILlo, R. T. Vibrotactile thresholds measured at the finger. Perception \& Psychophysics, 1971, 9, 329-330.

VERRILLO, R. T. Vibrotactile intensity scaling at several body sites. In F. A. Geldard (Ed.), Cutaneous communication systems and devices. Austin. Texas: The Psychonomic Society, 1974.

Verrillo, R. T., \& Chamberlain, S. C. The effect of neural density and contactor surround on vibrotactile sensation magnitude. Perception \& Psychophysics, 1972, 11, 117-120.

Verrillo, R. T.. Fraioli. A. J., \& Smith, R. L. Sensory magnitude of vibrotactile stimuli. Perception \& Psychophysics. 1969. 6. 366-372.

VoN BÉKÉsy, G. Similarities between hearing and skin sensations. Psychological Review', 1959, 66, 1-22.

WRIGHT, H. N. Loudness as a function of duration. Journal of the Acoustical Society of A merica, 1965, 37, 1174.

Zwislocki, J. J. Theory of temporal auditory summation. Journal of the Acoustical Society of America, 1960, 32, 1046-1060.

Zwislocki. J. Analysis of some auditory characteristics. In R. D. Luce, R. R. Bush, \& E. Galanter (Eds.), Handbook of mathematical psychology (Vol. 3). New York: Wiley, 1965. Pp. 1.97.

ZwISLOCKI, J. J. Temporal summation of loudness: An analysis. Journal of the Acoustical Society of America, 1969, 46, $431-441$.

(Received for publication April 18, 1976.) 